UDK: 821.134.2.09-1 Гарсија Лорка Ф. DOI: https://doi.org/10.18485/legado_hispanico.2020.ch6

\author{
Sergio García García ${ }^{1}$ \\ Universidad Autónoma de Madrid \\ España
}

\title{
«SI YO ME PIERDO, QUE ME BUSQUEN \\ EN ANDALUCÍA 0 EN CUBA»: LA MIRADA \\ ANTILLANA DE FEDERICO GARCÍA LORCA \\ A PARTIR DE «SON DE NEGROS EN CUBA»
}

\begin{abstract}
Resumen
Después de su conocida estancia en Nueva York, Federico García Lorca residió durante tres meses en Cuba. Dicha experiencia fue plasmada por el granadino en el último poema incluido en Poeta en Nueva York: «Son de negros en Cuba». El objetivo de este trabajo es determinar las distintas relaciones entre el contenido del poema con el viaje de García Lorca a Cuba, y justificar la naturaleza musical del texto, así como la intención del poeta con respecto a él, ya que se defiende que «Son de negros en Cuba» no responde a un anhelo lorquiano por visitar Santiago de Cuba, como podría entenderse a partir de una lectura literal del poema, sino que representa en esencia un homenaje a la propia isla de Cuba.

Palabras clave: García Lorca, Cuba, son, Santiago de Cuba, Poeta en Nueva York.
\end{abstract}

${ }^{1}$ sergio.garciag@uam.es 
En una carta fechada en Madrid en enero de 1929, Federico García Lorca escribe a su familia anunciándoles la oportunidad de realizar un viaje al otro lado del Atlántico, un viaje que, pasados los años, desembocaría en un libro: Poeta en Nueva York. El granadino les escribe lo siguiente:

Lo más importante que me pasa es que me han propuesto una tournée por América. Esto está todavía apenas iniciado pero me puede dar muchísimo dinero. Desde luego, ya os tendré al corriente de lo que me digan.

Yo [sic] lo aceptaría. Sería una tournée de conferencias por Cuba y las universidades norteamericanas.

Yo [sic] me gustaría hacer este viaje, que me podría proporcionar dinero y cultura (García Lorca 1997: 1091).

Un año y dos meses después de la redacción de esta carta, concretamente el 6 de marzo de 1930, García Lorca viaja en tren desde Nueva York a Tampa, en Florida, donde embarca en el vapor norteamericano de nombre Cuba con destino a La Habana. La mañana del día siguiente, el poeta desembarca en el muelle de La Habana, lugar al que regresará el 13 de junio de 1930 para tomar el barco que lo devuelva a su tierra natal, tras un año de ausencia (Gibson 1987: 81, 86, 122)². «Son de negros en Cuba» ${ }^{3}$ es el único testimonio poético de la experiencia antillana de García Lorca, fin de su periplo por el continente americano. Pero el poeta no narra en el poema dicha experiencia, sino que, a partir de su raíz, es decir, de todo lo vivido, lo aprendido, lo sentido y lo escuchado en la isla, construye un elenco de imágenes en el cual se reconoce la fotografía poética de una realidad determinada. «Son de negros en Cuba» es el fruto de la mirada personal de García Lorca hacia la Cuba que descubre y que lo cautiva en la primavera de 1930.

Aunque en la carta a su familia de enero de 1929 ya le menciona la idea de viajar a la isla, en una carta posterior dirigida a Carlos Morla Lynch y fechada en Granada el 6 de junio de 1929 asegura que a su regreso de Nueva York pasará unos meses en París en vez de en Cuba:

Estoy en Madrid dos días para ultimar unas cosas y en seguida salgo para París-Londres, y allí embarcaré a New York. ¿Te sorprende? A mí

\footnotetext{
${ }^{2}$ Andrew A. Anderson asegura que García Lorca llegó a Cuba en un ferry desde la isla de Cayo Hueso (en inglés Key West), perteneciente al archipiélago de Cayos de la Florida. Posiblemente, el poeta saliera desde la Península de Florida, es decir, desde Tampa hacia Cayo Hueso, y de ahí tomara un ferri con dirección a La Habana (Anderson 2013: 7).

${ }^{3}$ El texto de «Son de negros en Cuba» que se ha empleado para este estudio es el que recoge la edición de Poeta en Nueva York realizada por Anderson (García Lorca 2013: 281-282).
} 
también me sorprende. Yo estoy muerto de risa por esta decisión. Pero me conviene y es importante en mi vida. Pasaré en América seis o siete meses y regresaré a París para estar el resto del año. New York me parece horrible, pero por eso mismo me voy allí. Creo que lo pasaré muy bien. El viaje lo hago con mi gran amigo Fernando de los Ríos, viejo maestro mío y persona encantadora en extremo, que me allanará las primeras dificultades, ya que, como tú sabes, yo soy un inútil y un tontito en la vida práctica (García Lorca 1997: 1100).

Pero la isla regresa pronto a los planes de García Lorca: ya en Nueva York escribe en diciembre a su familia diciéndoles que «ya me han escrito de Cuba. Ya os contaré. Hoy no adelanto nada. Ya no adelanto ni digo nada mientras las cosas no sean hechos realizados» (García Lorca 1997: 1155); y un mes después, en enero de 1930, el poeta les confirma su viaje: «Ya es seguro que voy a Cuba en el mes de marzo. Onís me ha arreglado el viaje. Allí daré ocho o diez conferencias» (1997: 1157). Así, desembarca en marzo en La Habana.

En la conferencia dedicada a su periplo americano titulada «Un poeta en Nueva York», pronunciada por primera vez el 16 de marzo de 1932 en la Residencia de Señoritas de Madrid «bajo los auspicios del recién creado Comité de Cooperación Internacional» (Anderson 2013: 9), García Lorca describe la primera impresión que tuvo de La Habana, una imagen inicial que, más que de novedad, lo inundó de recuerdos y de una sorprendente familiaridad:

Pero el barco se aleja y comienzan a llegar, palma y canela, los perfumes de la América con raíces, la América de Dios, la América española.

¿Pero qué es esto? ¿Otra vez España? ¿Otra vez Andalucía mundial?

Es el amarillo de Cádiz con un grado más, el rosa de Sevilla tirando a carmín y el verde de Granada con una leve fosforescencia de pez.

La Habana surge entre cañaverales y ruido de maracas, cornetas chinas y marimbas. Y en el puerto, ¿quién sale a recibirme? Sale la morena Trinidad de mi niñez, aquella que se paseaba por el muelle de La Habana, por el muelle de La Habana paseaba una mañana ${ }^{4}$.

Y salen los negros con sus ritmos que yo descubro típicos del gran pueblo andaluz, negritos sin drama que ponen los ojos en blanco y dicen: «Nosotros somos latinos».

Con tres grandes líneas horizontales, línea de cañaveral, línea de terrazas y línea de palmeras, mil negras con las mejillas teñidas de naranja, como si tuvieran cincuenta grados de fiebre, bailan este son que yo compuse y que llega como una brisa de la isla (García Lorca 1997: 1173).

\footnotetext{
${ }^{4}$ Según Gibson, este personaje que evoca el poeta es el de una habanera que formó parte de su infancia en la Vega de Granada (1987: 84).
} 
El son al que se refiere es su poema «Son de negros en Cuba». Pero antes de tratar directamente esta composición, es preciso resaltar que en La Habana el granadino se topa de bruces con su Andalucía natal, no solo en lo que se refiere al paisaje, sino también al ritmo de la música cubana, y así se lo comunica a su familia en la primera carta que les envía desde Cuba, fechada en La Habana el 8 de marzo de 1930:

La llegada a La Habana ha sido un acontecimiento, ya que esta gente es exagerada como pocas. Pero Habana es una maravilla, tanto la vieja como la moderna. Es una mezcla de Málaga y Cádiz, pero mucho más animada y relajada por el trópico. El ritmo de la ciudad es acariciador, suave, sensualísimo, y lleno de un encanto que es absolutamente español, mejor dicho, andaluz. La Habana es fundamentalmente española, pero de lo más característico y más profundo de nuestra civilización. Yo naturalmente me encuentro como en mi casa. Ya vosotros sabéis lo que a mí me gusta Málaga, y esto es mucho más rico y variado. Por ahora no sé deciros más. A cada momento tengo la impresión de encontrarme a los amigos detrás de la esquina y a cada momento tengo que pensar que estoy en el mar Caribe, en las hermosísimas Antillas, para no hacerme en Vélez o en Motril. El mar es prodigioso de colores y luz. Se parece al Mediterráneo, aunque es más violento de matices (García Lorca 1997: 1164-1165).

Cuando García Lorca finaliza los poemas que compondrán Poeta en Nueva York, inicialmente decide incluir en el poemario «dibujos, fotografías, tarjetas postales (se presume que fotográficas) y fotomontajes» que fue recopilando en su viaje por Estados Unidos y Cuba, pero pronto se desprende de esa idea aconsejado por José Bergamín, quien iba a ser el editor del libro (Anderson 2013: 126-130). El poema «Son de negros en Cuba», la última composición del poemario y el único poema de la última sección del libro titulada «El poeta llega a La Habana», iba a estar acompañado por una fotografía titulada «Paisaje de La Habana» y que muestra la Bahía de La Habana con el Faro del Morro al fondo ${ }^{5}$.

Desde el mar caribeño que salpica la costa habanera, recibe García Lorca la primera impresión del lugar donde pasará los tres meses que lo separan de Nueva York y de España. En el muelle de La Habana al poeta le reciben «un nutrido grupo de intelectuales, escritores y artistas cubanos», y se instala en el hotel La Unión, situado «en medio de un laberinto de calles estrechas con enrejadas ventanas, que al poeta le recordaron en seguida a Cádiz», como invitado de la Institución Hispano-Cubana de Cultura (Gibson 1987: 86), cuyo presidente era en aquel tiempo Fernando

\footnotetext{
${ }^{5}$ Dicha imagen se puede ver en García Lorca, 2006: 232.
} 
Ortiz, musicólogo, jurista y antropólogo (Soria Olmedo 2013: 441), persona a quien García Lorca dedica «Son de negros en Cuba». Ortiz invita al granadino a dar una serie de conferencias en La Habana, concretamente en el Teatro Principal de la Comedia: el 9 de marzo García Lorca pronuncia «La mecánica de la poesía», versión de «Imaginación, inspiración, evasión en la poesía», conferencia ya pronunciada en Nueva York; el 12 de marzo, «Paraíso cerrado para muchos, jardines abiertos para pocos. Un poeta gongorino en el s. XVII», y el 16 de marzo, «La imagen poética de don Luis de Góngora» (Gibson 1987: 88). Las dos últimas conferencias que pronuncia el poeta en La Habana, «La imagen poética de Luis de Góngora» el 19 de marzo y «La arquitectura del cante jondo» el 6 de abril, se las envían sus padres a finales de enero de 1930 a Nueva York —el poeta se las pide en la carta ya citada fechada en Nueva York en enero de 1930, en la cual les confirma su viaje a Cuba-, y García Lorca les contesta lo siguiente:

Hoy mismo recibí las conferencias. La del cante jondo sólo me servirá para algunos detalles, pero la de Góngora me será más útil. Por eso os ruego que hagáis el favor de enviarme las cinco últimas hojas [...] Yo quisiera que me la enviaseis en seguida [...] Porque es la parte de la muerte de Góngora, que es a propósito para la gente sentimental de Cuba (García Lorca 1997: 1162).

Era tanta la admiración que «la gente sentimental de Cuba» sentía por el poeta granadino que la Institución Hispano-Cubana amplía su programa de conferencias (Leante 1986: 236). Así, el 7 de abril y el 5 de junio pronuncia dos conferencias más en la ciudad de Cienfuegos, y el 2 de junio, «Mecánica de la poesía» en la Escuela Normal de Maestras de Santiago de Cuba, ciudad presente en su «Son de negros en Cuba» (Iturria Savón 2006: 24).

García Lorca tenía previsto acudir a Santiago de Cuba a principios de abril, pues tenía programada una conferencia para el día 5 de ese mes (Rabassó \& Rabassó 1998: 463), pero debido a que al día siguiente debía pronunciar otra conferencia en La Habana, el poeta no viajará a Santiago de Cuba hasta finales del mes siguiente. El granadino parte de La Habana en tren el 31 de mayo y llega a Santiago de Cuba al día siguiente; en la estación es recibido por Max Henríquez Ureña, presidente de la Institución Hispano-Cubana de esa ciudad (Soria Olmedo 2013: 445).

Algunos conocidos del poeta siempre dudaron de su visita a Santiago de Cuba, como es el caso del músico español Antonio Quevedo, quien, junto con su mujer María Muñoz, llevaba desde 1919 viviendo en 
Cuba (Leante 1986: 236-237); en cuanto García Lorca llegó a La Habana, acudió a visitarlos. El matrimonio había creado la revista Musicalia (Gibson 1987: 87), y es en el número de abril-mayo de 1930, en las páginas 43 y 44, donde García Lorca publica por primera vez «Son de negros en Cuba», aunque con un título más reducido: «Son» (Soria Olmedo 2013: 445). Antonio Quevedo pudo dudar del viaje del granadino a Santiago de Cuba por dos razones: bien por simple desconocimiento, bien porque el poema fue compuesto en abril de 1930 (Anderson 2013: 58), esto es, antes de que García Lorca visitará la ciudad. Guillermo Cabrera Infante establece que aquellos que cuestionan la estancia del poeta en Santiago de Cuba son aquellos «que consideran la poesía como una acción metafórica» (1986: 224); Cabrera Infante olvida, como se acaba de mencionar, que García Lorca compuso el poema antes de conocer la ciudad, por lo que en él no narra ningún tipo de viaje ni experiencia, sino que desarrolla un texto que bien podría considerarse un homenaje a toda la isla. Entonces, en este caso particular, sí que habría en «Son de negros en Cuba» un fuerte contenido metafórico, como se intentará demostrar más adelante.

Poco se sabe de la estancia de García Lorca en Santiago de Cuba, salvo que se hospeda en el hotel Venus, paradero «de artistas, escritores y cuanta gente distinguida visitaba por esa época la ciudad» (Gibson 1987: 97), y que visita el Santuario de Nuestra Señora de la Caridad del Cobre, pues a su vuelta le regala a su amiga Flor Loynaz una medallita de la virgen. Los Loynaz, «una excéntrica, aristocrática y rica familia de cuatro hermanos poetas y artistas: Flor, Enrique, Carlos Manuel y Dulce María», a cuya finca del barrio habanero del Vedado acudía García Lorca a diario, nunca supieron nada más de su viaje al oeste de la isla; es más, el granadino, a pesar de la amistad que le unía a dicha familia - sobre todo a Flor y a Carlos Manuel, con quienes «recorre noche tras noche antros y tascas de La Habana Vieja y sus alrededores»-, nunca les informó de su partida. Los Loynaz se enteraron de ello por el personal del hotel La Unión, al no acudir García Lorca a su finca después del almuerzo (Gibson 1987: 99-102).

Su interés por visitar y conocer Santiago de Cuba aumenta cuando descubre que de allí procede el son (Cabrera Infante 1986: 245), género musical cubano que conoce en La Habana y que le conquista desde un primer momento. En una entrevista publicada en el Heraldo de Madrid el 9 de octubre de 1930, Miguel Pérez Ferrero le pregunta al poeta por aquello que más le ha impresionado de Cuba, a lo que García Lorca contesta: «A mí, su música. Después de terminada mi actuación de conferenciante, yo me quedé a estudiar la música». Tanta es la fascinación que desarrolla por la música cubana que, en la misma entrevista, le confiesa al Pérez Ferrero 
que desea regresar a la isla para continuar indagando en su cultura musical (García Lorca 1997: 372). Sobre esta pasión que se despierta en el interior del poeta por el son cubano, Adolfo Salazar, en un testimonio de 1938, recuerda la siguiente anécdota:

En La Habana [García Lorca] era el mejor conocedor de sones y soneros. Se había hecho amigo de los morenos de los sextetos y no había noche que la excursión no terminara en las «fritas» de Marianao. Primero, escuchaba muy seriamente. Luego, con mucha timidez, rogaba a los soneros que tocasen este o aquel son. En seguida probaba las claves, y como había cogido el ritmo, y no lo hacía mal, los morenos reían complacidos haciéndole grandes cumplimientos. Esto le encantaba: un momento después, Federico acompañaba a plena voz y quería ser él quien cantase la copla. Algunas letras le hacían morir de risas (Anderson \& Maurer 2013: 327-328).

El son que cautiva a García Lorca se define como un "género vocal, instrumental bailable, que constituye una de las formas básicas dentro de la música cubana» y cuya estructura presenta elementos de procedencia tanto africana como española (Orovio 1992: 455). El granadino, quien ya estaba «completamente aplatanado» al mes de estar en La Habana (Roig de Leuchsenring 2006: 54), al regresar de una visita a la ciudad de Matanzas (Gibson 1987: 95), compone un son: su «Son de negros en Cuba». El poema, pues, como se ha ido adelantando en las líneas anteriores, no es una traslación poética de su experiencia antillana, sino, simplemente, una canción, un son que García Lorca dedica al territorio cubano. Es entonces la música, la música cubana en este caso, el germen de «Son de negros en Cuba», como ya lo fuera de algunas de sus primeras obras, como Poema del cante jondo, Suites y Canciones.

Una de las características fundamentales y más representativas del son cubano es la presencia de un estribillo de cuatro compases llamado montuno que se repite a lo largo de toda la pieza (Orovio 1992: 456-457). En «Son de negros en Cuba» el estribillo es un pentasílabo heroico, «Iré a Santiago», que García Lorca repite en dieciocho ocasiones dentro de los treinta y siete versos que forman el poema. La presencia de un estribillo en el poema viene dada por la propia naturaleza del son, aunque Soria Olmedo considere que es la influencia de la tradición clásica española lo que mueve a García Lorca a construir el poema en torno a un estribillo, ya que en el comienzo del acto III de La dama boba de Lope de Vega, obra que el granadino «adaptó para la compañía de la actriz Eva Franco y se estrenó en 1934, en Buenos Aires», ya aparece un estribillo compuesto de 
un verbo direccional acompañado de un topónimo: «Viene de Panamá» (Soria Olmedo 2013: 449-450). Asimismo, según establece GarcíaPosada, «la fidelidad del estribillo», que tanto recuerda a su vez al poema «La cogida y la muerte», la primera parte del Llanto por Ignacio Sánchez Mejías, es la característica que determinada la clasificación de «Son de negros en Cuba» como un poema tradicional, frente al resto de poemas de Poeta en Nueva York, que estarían en una posición intermedia entre la métrica tradicional y el verso libre (García-Posada 1981: 195-196). También, la aparición del nombre de Santiago de Cuba en el estribillo, así como en el primer verso del poema, ha generado toda esa mitología que gira alrededor de la estancia de García Lorca en dicha ciudad.

El hecho de que el poema sea una canción, sitúa la musicalidad global del poema en la ya mencionada repetición del estribillo y en la presencia de la rima asonante, tanto en el interior como al final del verso. Por su parte, García Lorca alterna metros pares (octosílabos y un decasílabo) con impares (pentasílabos y endecasílabos), así como con algunos metros hemistiquiales (alejandrinos [7+7] y un heptadecasílabo [9+8]), por lo cual la regularidad rítmica de los versos, fundamentada en las disposiciones de los acentos tónicos, no es homogénea. Tomás Navarro Tomás asegura que, aunque refiriéndose al metro octosilábico, la ejecución de las distintas posibilidades rítmicas por parte de García Lorca depende solamente de su intuición y de su sensibilidad (2014: 359), idea que bien se podría aplicar a los metros que componen este poema. La musicalidad de «Son de negros en Cuba», pues, no depende del ritmo interno del verso, sino de su configuración estructural.

Con respecto a la rima asonante, rima que poseen todos los versos del poema, destaca, en primer lugar, la rima en á-o, por la constante repetición de «Santiago», así como por la presencia de otras palabras como «plátano», «tabaco» y «barro», y, en segundo lugar, la rima en é-a, que, en la mayor parte de las ocasiones, se alterna con la rima en á-o. También, aunque en menor medida, el granadino se sirve de la rima asonante interna: así, en los vv. 29 y 31 «coral» y «mar» riman entre sí; en el v. 1, «luna» $\mathrm{y}$ «Cuba» — asimismo, el adjetivo «llena», situado al final del primer hemistiquio de este verso, rima en é- $a$ con el v. 3-; en los vv. 18 y 20, «cintura» y «Cuba», y en el v. 36, de nuevo «Cuba» con «curva». Por último, en el v. 33 «blanco», aunque esté en el interior del verso, rima en $a ́$ - $o$ con el verso que la antecede y la precede, ambos con la palabra «Santiago» al final; la pausa interna que genera la coma en el v. 33 - «Calor blanco, fruta muerta»- crea una cadencia bastante elaborada, pues la palabra final de este verso, «muerta», rima en asonante con los versos 
situados dos posiciones por encima y por debajo. Un caso parecido es el de los vv. 1 y 2 , a causa de la repetición de «Santiago» en dos ocasiones: en el interior del v. 1 y al final del v. 2.

Como se ha mencionado anteriormente, García Lorca utiliza tanto metros pares como impares para componer "Son de negros en Cuba», lo que lleva a la dislocación del ritmo homogéneo del poema en algunos momentos puntuales, sobre todo a causa del empleo del octosílabo, como se muestra a continuación:

17 Cuando llegue la luna llena iré a Santiago de Cuba,

5 iré a Santiago

2.4

8 en un coche de agua negra.

3.5.7

5 Iré a Santiago.

2.4

510 Cantarán los techos de palmera.

3.5.9

5 Iré a Santiago.

2.4

11 Cuando la palma quiere ser cigüeña

4.6.8.10

5 iré a Santiago.

2.4

11 Y cuando quiere ser medusa el plátano

4.6.8.10

105 iré a Santiago.

2.4

5 Iré a Santiago

2.4

11 con la rubia cabeza de Fonseca.

3.6 .10

5 Iré a Santiago.

2.4

11 Y con el rosa de Romeo y Julieta

4.8 .10

155 iré a Santiago.

2.4

11 Mar de papel y plata de moneda.

1.4.6.10

5 Iré a Santiago.

2.4

11 ¡Oh Cuba! ¡Oh ritmo de semillas secas!

2.4.8.10

5 Iré a Santiago.

2.4

2014 ¡Oh cintura caliente y gota de madera!

$3.6+2.6$

5 Iré a Santiago.

2.4

14 Arpa de troncos vivos. Caimán. Flor de tabaco.

$1.4 .6+2.3 .6$

5 Iré a Santiago.

2.4

11 Siempre he dicho que yo iría a Santiago

1.4.(7).8.10

258 en un coche de agua negra.

3.5 .7

2.4

5 Iré a Santiago.

1.4.7

8 Brisa de alcohol en las ruedas.

2.4

5 Iré a Santiago.

8 Mi coral en la tiniebla. $\quad 3.7$

305 Iré a Santiago.

2.4

8 El mar ahogado en la arena.

2.4 .7

5 Iré a Santiago.

2.4

8 Calor blanco, fruta muerta.

(2).3.5.7

5 Iré a Santiago.

2.4

3.6 .10

3511 ¡Oh bovino frescor de cañaveras!

2.4.8.10

11 ¡Oh Cuba! ¡Oh curva de suspiro y barro!

5 Iré a Santiago.

2.4 
Íntimamente ligada al son está la figura del afrocubano. El son en su esencia es un baile para bailar en pareja, y son los negros y las negras habaneros los que lo bailan, así como aquellos que lo interpretan. Esta relación tan estrecha y necesaria la menciona García Lorca directamente en el título de su poema; aunque solo aparezcan en una ocasión en todo el texto, son los afrocubanos los receptores de «Son de negros en Cuba». Pero aquellos que el granadino encuentra en La Habana y en todo el territorio cubano no son, en palabras de Francisco Umbral, esa «otra raza proscrita, como los gitanos» que conoce en Nueva York (2011: 154), sino que son los protagonistas de su tierra, los dueños y creadores de su cultura. García Lorca canta y se deja cautivar por la alegría del pueblo negroide cubano, porque en él no ve represión ni exclusión como sí lo hizo en Estados Unidos.

Durante sus días neoyorquinos, el granadino ya descubre al pueblo cubano: en una carta fechada el 14 de julio de 1929 le cuenta a su familia que una de sus compañeras de clase de inglés en Columbia University es «una cubana de sesenta años pintadísima que se llama Ofelia», así como que es también allí donde descubre la belleza de la mujer negra (García Lorca 1997: 1113-1114). Una vez en La Habana García Lorca reafirma estas impresiones neoyorquinas. En una carta a su familia, aunque esta vez desde La Habana, fechada el 5 de abril de 1930, escribe:

Anteayer me ofrecieron un té las damas distinguidas de La Habana en un Lyceum Club. Allí vi las mujeres más hermosas del mundo. Esta isla tiene más bellezas femeninas de tipo original, debido a las gotas de sangre negra que llevan todos los cubanos. Y cuanto más negro, mejor. La mulata es la mujer superior aquí en belleza y en distinción y en delicadeza (García Lorca 1997: 1168).

También, en La Habana el poeta conoce la belleza del hombre negro cubano, pues mantiene un romance «con un bello y vigoroso mulato de veinte años llamado Lamadrid, bajito de cuerpo y con piel café claro, a quien la gente recuerda por sus ampulosas gesticulaciones y modales cursis» (Gibson 1987: 106). En definitiva, no solo la belleza del pueblo cubano le hace sentirse fuera del mundo cotidiano e imperfecto - «Esta isla es un paraíso» les asegura a sus padres (García Lorca 1997: 1168)—; también el folclore de los negros abre una nueva puerta para su imaginario poético y personal, y de ahí la composición de «Son de negros en Cuba» y la inserción de la experiencia antillana en otras de sus obras, como podría suceder, según establece Ian Gibson, en El público, haciendo referencia a «la 
Dominga de los negritos», personaje con el cual se identifica el Director y que hace alusión «a una célebre bailarina que actuaba en un establecimiento del puerto de La Habana» frecuentado por el granadino (1987: 113).

La estructura de «Son de negros en Cuba» sigue en su mayor parte el esquema formal del son: el estribillo se intercala por lo general con un verso que equivale a una o varias imágenes aisladas, salvo en los vv. 10 y 9, donde el estribillo se repite dos veces, y en los vv. 24 y 25 , y 35 y 36, donde las imágenes autónomas ocupan dos versos. Algunas de estas imágenes aluden en parte al futuro viaje a Santiago de Cuba que realizará el sujeto lírico: en los vv. 1 y 24 la alusión es clara: «Cuando llegue la luna llena iré a Santiago de Cuba» y «Siempre he dicho que yo iría a Santiago». Otros versos desvelan cómo se realizará el viaje - «en un coche de agua negra», vv. 3 y 25-, cuándo se llevará a cabo - el ya citado v. 1 y los vv. 7-10: «Cuando la palma quiere ser cigüeña / iré a Santiago. / Y cuando quiere ser medusa el plátano / iré a Santiago»-y los elementos que acompañarán al visitante — «Iré a Santiago / con la rubia cabeza de Fonseca. / [...] Y con el rosa de Romeo y Julieta / iré a Santiago», vv. 1115-. Las referencias constantes al deseo de acudir a Santiago de Cuba no se deben interpretar en un sentido literal; el viaje es la excusa que García Lorca encuentra para escribir un son cubano. El resto de imágenes son, fundamentalmente, impresiones sobre el contexto antillano.

Dejando a un lado el viaje y el topónimo, la llegada de «la luna llena» que recoge el v. 1 recuerda directamente a un dibujo que realiza García Lorca durante su estancia cubana: Teorema de la mujer que se come la luna, fechado en La Habana en 1930 (Hernández 1990: 202). Aunque el primer verso del poema no posea ningún significado poético, sino que, más bien, sirve exclusivamente para introducir el motivo estructural del poema, a partir del v. 3 el poeta inicia la sucesión de metáforas que ocupa toda la composición hasta su penúltimo verso. En el v. 3, y en el v. 25, el sujeto lírico establece que acudirá a Santiago de Cuba «en un coche de agua negra»; aún la crítica no se ha puesto de acuerdo sobre la determinación del significado de ese "coche de agua negra», pues las opiniones son muy distintas. La interpretación más coherente y posiblemente más certera, como plantea Gibson, es que el «coche de agua negra» sea el tren Central Habana-Santiago «con su denso humo negro» que García Lorca tenía pensado tomar para ir a Santiago de Cuba - recuérdese que la composición del texto es anterior al viaje-, medio de transporte con el que finalmente se desplaza a dicha ciudad (1987: 97). García-Posada, por su parte, considera que el «coche» es un barco de vapor que, para llegar a Santiago de Cuba, tiene que atravesar el «agua negra» de «esta 
zona del Atlántico, muy cercana al mar de los Sargazos», característico por su color oscuro (1981: 142); Gibson también plantea esta posibilidad interpretativa, estableciendo que este barco de vapor es, concretamente, «un vapor a ruedas» (1987: 97), lo cual se relaciona con el v. 27, «brisa de alcohol en las ruedas», aunque, al margen de la imagen de la ebriedad producida por el ron, esas «ruedas» también pueden ser perfectamente las ruedas del tren. Otros, en las antípodas de las interpretaciones anteriores, han visto en el "coche de agua negra» una berlina de charol negro, fruto de las fantasías decimonónicas de la infancia de García Lorca, según establece Soria Olmedo (2013: 449); Leante comparte la misma interpretación de Soria Olmedo, aunque sitúa el origen de la berlina en otro lugar: durante el tiempo que reside García Lorca en La Habana se crea una leyenda sobre una cena que se sirvió en la finca de los Loynaz «en la que todos los comensales vestían de negro y arribaban en coches también negros tirados por caballos negros» (1986: 238).

El «coche de agua negra» podría ser la imagen más críptica de «Son de negros en Cuba», pero más clara es la interpretación de otras imágenes, a la cual se puede llegar a través de los testimonios de algunos conocidos de García Lorca a los que desveló algunas de las claves del poema. Este es el caso del testimonio de Juan Marinello, a quien confesó que los vv. 12 y 14 , «con la rubia cabeza de Fonseca» y «Y con el rosa de Romeo y Julieta» respectivamente, hacen referencia a «los estuches de tabacos que de La Habana le enviaban a su padre, hasta su infantil Fuentevaqueros». Así, el v. 12 alude directamente al señor Fonseca, cuyo rostro aparecía en los estuches de habanos de la Fábrica de Tabacos de su mismo nombre. Cuenta Marinello que «agradó a Federico saber que el señor Fonseca, a quien había yo tratado mucho [...], había sido hombre de muy buena sensibilidad y amigo y protector de artistas» (Anderson y Maurer 2013: 331).

También «Romeo y Julieta» es una marca de habanos, y en el v. 14 se hace referencia al color rosa de la cinta en donde el nombre está inscrito (Leante 1986: 239). Adolfo Salazar cuenta una anécdota referida a la escena que se muestra en esta caja de puros, durante un paseo nocturno acompañado del granadino por el pueblo de Caimito del Guayabal:

La casita de campo era de cedro. Dentro de ella se respira un aroma exquisito.

-Esta es la casa de Romeo y Julieta — sentenció Federico y nos anunció incontinente que iba a hacer un drama donde el personaje principal tuviese la barba dorada de Fonseca. Desde la galería veíamos ponerse el sol y tomábamos sorbetes (Anderson \& Maurer 2013: 329). 
Guardan también relación con los habanos los vv. 16, «Mar de papel y plata de moneda», y 29, «Mi coral en la tiniebla». Por un lado, el v. 16, según Leante, es una metáfora de «las policromadas vitolas de los habanos» (1986: 239), pero, si se atiende a las imágenes recogidas en la página anterior que muestran las insignias de las dos marcas de habanos, se aprecia en las dos tanto la presencia de monedas plateadas, como, en el caso de la Fábrica de Tabacos Fonseca, una ilustración en el lado derecho del papel de la Bahía de La Habana con el Faro del Morro al fondo, misma imagen que la fotografía que García Lorca quería incluir al lado de «Son de negros en Cuba» en Poeta en Nueva York. Por otro lado, el «coral en la tiniebla» del v. 29 hace referencia a la lumbre roja del habano que ilumina el rostro de quien lo fuma por la noche. Para García-Posada, el habano «es un símbolo de vida, de despreocupación, de alegría exultante; un símbolo, que es un deseo, y por eso mucho más punzante, ya que las huellas del infierno irán quemando la piel» (1981: 106).

El v. 22 contiene tres imágenes distintas: «Arpa de troncos vivos», «Caimán» y «Flor de tabaco». La tercera de nuevo hace referencia al tabaco habano, y la primera y la segunda se pueden interpretar gracias al propio testimonio de García Lorca. En primer lugar, el «arpa de troncos vivos» es una imagen de toda la isla de Cuba, según las impresiones del poeta. Sobre ello, cuenta Marinello que al granadino, «al atravesar el suave arco sellado de palmeras que es nuestra isla, le quedaba la visión de un arpa gigantesca formada por millones de troncos sonoros, esperando que una mano descomunal, la mano de un dios músico, le arrancase una sinfonía queda y caliente» (Soria Olmedo 2013: 453). Y, en segundo lugar, la mención del «caimán» puede hacer referencia a una cacería de cocodrilos a la que asiste García Lorca al mes de llegar a Cuba, que le relata a su familia en una carta fechada en La Habana el 5 de abril de 1930 (García Lorca 1997: 1167-1168).

La música cubana no solo configura la estructura formal y el sentido del poema, sino que además acapara algunas imágenes del texto, concretamente, aquellas que contienen los vv. 18 y 20: « ¡Oh Cuba! ¡Oh ritmo de semillas secas!» y « $\mathrm{Oh}$ cintura caliente y gota de madera!». Estos dos versos aluden directamente al son: García Lorca decide hacer una referencia metafórica a dos de los instrumentos que componen la orquesta que acostumbra a interpretar los sones: las maracas y las claves (Orovio 1992: 457). Por tanto, según establece Cabrera Infante, «la gota de madera» hace una referencia directa a las claves y el «ritmo de semillas secas», al ritmo de las maracas (1986: 245). La «cintura caliente» también tiene una vinculación bastante marcada con el son, pues con esta imagen 
García Lorca, en opinión de García-Posada, describe la vitalidad de las parejas de bailarines cubanos que desprende una «evidente tensión erótica» (1981: 142).

El resto de imágenes que construyen el texto son, en su esencia, las distintas impresiones que recibe el granadino al observar el paisaje cubano, lo cual lleva a confirmar que el tema principal de «Son de negros en Cuba» no es el anhelo por conocer la ciudad de Santiago de Cuba, sino, simplemente, la isla en todos sus ámbitos: folclore, paisaje, etc. En el v. 5 se alude a la vida del pueblo cubano que se desarrolla debajo de «los techos de palmera» que cantarán a su llegada a Santiago de Cuba, que son «los techados de los bohíos, vivienda tradicional campesina hecha toda con hojas, troncos y fibras de la palma real» (Cabrera Infante 1986: 245). Asimismo, para la descripción del paisaje cubano se sirve de la convivencia de la flora y la fauna de la isla en un mismo verso para expresar «la exhuberancia [sic] vegetal del trópico» (García-Posada 1981: 91): «Cuando la palma quiere ser cigüeña», v. 7; «Y cuando quiere ser medusa el plátano», v. 9, y «iOh bovino frescor de cañaveras!», v. 35. Lo vegetal aspira a lo animal, pero en esencia y en apariencia son lo mismo, pues, en palabras de Emilio Ballagas, «nuestras palmeras - las palmas-duermen como las cigüeñas, la hipotética cabeza extendida debajo de las plumas del macho y en un solo pie, eternamente, sin que ningún susto posible les haga "poner en tierra la otra pata"» (2006: 62). El poeta aúna, por tanto, lo natural con lo humano, ambos elementos se sumergen el uno en el otro en todo el poema, como en el v. 31 el mar se ahoga en la arena caliente cubierta de «frutas ya putrefactas» (García-Posada 1981: 142) — «Calor blanco, fruta muerta», v. 33-. En definitiva, García Lorca homenajea la tierra que lo acoge con una canción elaborada a partir de lo vivido allí, y a partir de su imaginario y de sus recuerdos de su infancia andaluza. Cuba, pues, es la protagonista del son lorquiano, y con ella finaliza el poema: la «curva de suspiro y barro» del v. 36 es la propia isla, representada, en este caso, por su curva geográfica (Rabassó \& Rabassó 1998: 470-471).

El 7 de marzo de 1930 Federico García Lorca llega a La Habana como un invitado, como un huésped procedente de Estados Unidos, pero ya desde el primer contacto desde el mar con el horizonte cubano comienza a desprenderse de su traje de visitante. García Lorca descubre en la isla de Cuba que su Andalucía natal es universal, porque también existe en las calles de La Habana, de Matanzas, de Santiago de Cuba, así como en el son que cantan y bailan los negros que también son como él: latinos, españoles y andaluces. 
El conjunto poemático de Poeta en Nueva York se cierra, como ya se ha mencionado, con un homenaje musical a todo el territorio cubano: «Son de negros en Cuba», un texto que ya empieza a gestarse en los juegos infantiles del Federico niño en Fuentevaqueros y que se nutre de todos los paisajes que la mirada del poeta va captando de punta a punta de la isla, hasta alcanzar su resultado en un sitio cualquiera de La Habana durante el mes de abril. Cuando García Lorca compone su «Son de negros en Cuba», no lo hace con una mirada andaluza, sino con una mirada antillana, aunque, al fin y al cabo, ambas miradas son la misma, como ambos sitios, Andalucía y Cuba, son para García Lorca el mismo. «Si yo me pierdo - escribe el poeta-, que me busquen en Andalucía o en Cuba» (García Lorca 1997: 1168).

\section{REFERENCIAS BIBLIOGRÁFICAS}

Anderson 2013: Andrew A Anderson. «Introducción». Federico García Lorca, Poeta en Nueva York. Andrew A. Anderson (ed.). Barcelona: Galaxia Gutenberg / Círculo de Lectores, 7-138.

Anderson \& Maurer 2013: Andrew A. Anderson \& Christopher Maurer. Federico García Lorca en Nueva York y La Habana: Cartas y recuerdos. Barcelona: Galaxia Gutenberg / Círculo de Lectores.

Ballagas 2006: Emilio Ballagas. «Un recuerdo de García Lorca». Miguel Iturria Savón (ed.), Miradas cubanas sobre García Lorca. Sevilla: Renacimiento, 59-67.

Cabrera Infante 1986: Guillermo Cabrera Infante. «Lorca hace llover en La Habana». Cuadernos hispanoamericanos, 433-434: 241-248.

García Lorca 1997: Federico García Lorca. Obras completas III. Prosa. Miguel García-Posada (ed.). Barcelona: Galaxia Gutenberg / Círculo de Lectores.

García Lorca 2006: Federico García Lorca. Poeta en Nueva York. María Clementa Millán (ed.). (14. eㅡ.) Madrid: Cátedra.

García Lorca 2013: Federico García Lorca. Poeta en Nueva York. Andrew A. Anderson (ed.). Barcelona: Galaxia Gutenberg / Círculo de Lectores. García-Posada: 1981: Miguel García-Posada. Lorca: interpretación de Poeta en Nueva York. Madrid: Akal.

Gibson 1987: Ian Gibson. Federico García Lorca. Vol. II. Barcelona: Grijalbo. Hernández 1990: Mario Hernández. Libro de los Dibujos de Federico García Lorca. Madrid: Ediciones Tabapress / Fundación Federico García Lorca. 
Iturria Savón 2006: Miguel Iturria Savón. «La ruta cubana de García Lorca». Miguel Iturria Savón (ed.), Miradas cubanas sobre García Lorca. Sevilla: Renacimiento, 15-32.

Leante 1986: César Leante. «Federico en Cuba». Cuadernos Hispanoamericanos, 433-434: 235-240.

Navarro Tomás 2014: Tomás Navarro Tomás. Los poetas en sus versos: desde Jorge Manrique a García Lorca. Madrid: Centro para la Edición de los Clásicos Castellanos.

Orovio 1992: Helio Orovio. Diccionario de la música cubana. Biográfico y

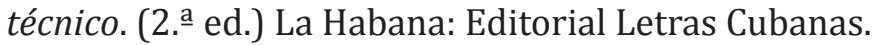

Rabassó \& Rabassó 1998: Carlos A. Rabassó \& Francisco Javier Rabassó. Granada - Nueva York - La Habana. Federico García Lorca entre el flamenco, el jazz y el afrocubanismo. Madrid: Ediciones Libertarias.

Roig de Leuchsenring 2006: Emilio Roig de Leuchsenring. «Federico García Lorca, poeta ipotrocasmo». Miguel Iturria Savón (ed.). Miradas cubanas sobre García Lorca. Sevilla: Renacimiento, 51-58.

Soria Olmedo 2013: Andrés Soria Olmedo. «Cuba en un poema de Federico García Lorca». Anales de la Literatura Española Contemporánea, 38/ 1-2: 441-459.

Umbral 2011: Francisco Umbral. Lorca, poeta maldito. Barcelona: Austral.

\section{«SI YO ME PIERDO, QUE ME BUSQUEN AN ANDALUCÍA O EN CUBA»: THE ANTILLEAN LOOK OF FEDERICO GARCÍA LORCA FROM «SON DE NEGROS EN CUBA»}

\section{Summary}

After his well-known stay in New York, Federico García Lorca lived in Cuba for three months. That experience was captured by the Grenadian in the last poem included in Poeta en Nueva York: «Son de negros en Cuba». The goal of this work is to determine the different relationships between the content of the poem and the trip of García Lorca to Cuba. Additionally, it is intended to justify the musical nature of the text, as well as the poet's purpose with it. It is defended that the poem "Son de negros en Cuba» does not meet a wish from the poet to visit Santiago de Cuba, as it could be understood from a literal first reading of the poem. Instead, it essentially represents homage to the Cuban island itself. York.

Keywords: García Lorca, Cuba, son, Santiago de Cuba, Poeta en Nueva 